\title{
EFEKTIVITAS MEDIA APLIKATIF DALAM PEMBELAJARAN AKSARA "KA GA NGA" SEBAGAI UPAYA MELESTARIKAN KEARIFAN LOKAL SUKU REJANG BENGKULU UTARA
}

\author{
Pahlawan, Sutejo Prabowo, Muhammad Mudzofar, Akbar Marfu' Alam R. \\ albatolunalbatolun97@gmail.com \\ Mahasiswa Fakultas Agama Islam
}

\begin{abstract}
ABSTRAK
Tujuan penelitian ini adalah untuk menguji efektivitas penggunaan media aplikatif pada pembelajaran aksara Rejang "Ka Ga Nga" dan sebagai upaya pelestarian kearifan lokal aksara dari Suku Rejang di Kabupaten Bengkulu agar dikenal oleh masyarakat luas. Hal ini dilatarbelakangi karena pembelajaran aksara Rejang "Ka Ga Nga" masih dianggap sulit, dan dalam proses pembelajaran di sekolah masih konvensional yaitu focus dengan buku. Guru tidak menggunakan media pembelajaran sehingga "Ka Ga Nga" menjadi pembelajaran yang membosankan. Metode yang digunakan dalam penelitian ini adalah Action Research. Memiliki tahapan yaitu: (1) identifikasi masalah, (2) analisis masalah beserta faktor penyebabnya, (3) formulasi pemecahan, (4) pencarian data pendukung, (5) formulasi aksi, dan (6) evaluasi. Diharapkan melalui penelitian ini dapat meningkatkan kualitas pembelajran aksara Rejang "Ka Ga Nga” khususnya di Sekolah Dasar Bengkulu Utara. Luaran dari PKMP SH ini adalah berupa buku panduan pembelajaran dan publikasi ilmiah berbentuk artikel.
\end{abstract}

Kata Kunci: Ka Ga Nga, Media Aplikatif, Kearifan Lokal, Suku Rejang.

\section{PENDAHULUAN}

\section{Latar Belakang}

Salah satu syarat utama bagi sebuah bangsa untuk bisa diakui cerdas dan memiliki tingkat peradaban yang tinggi adalah dengan adanya tulisan yang mereka miliki. Dengan kata lain bangsa tersebut harus memiliki huruf huruf tulisan sebagai alat komunikasi atau untuk keperluan kehidupan sosial mereka yang lainnya. Indonesia memiliki beragam aksara dari sabang sampai merauke. Aksara Nusantara merupakan beragam aksara atau tulisan yang lazim digunakan di Indonesia, secara khusus menuliskan bahasa daerah tertentu, walaupun abjad Arab dan alfabet Latin juga seringkali digunakan dalam menuliskan bahasa daerah.

Istilah Aksara Nusantara sendiri kerap dikaitkan dengan aksara hasil inkulturisasi kebudayaan India sebelum berkembangnya Islam dan sebelum zaman kolonialisasi di Indonesia. Berbagai macam media tulis dan alat tulis digunakan untuk menuliskan Aksara Nusantara, dari prasasti yang terbuat dari batu, kayu, tanduk hewan, lempengan emas, perak, tembaga serta perunggu dengan terlebih dahulu dipahat, hingga dalam bentuk naskah baik menggukan media daun lontar, nipah, janur kelapa, bilah bambu dan lainnya.

Salah satu aksara yang dikenal di Indonesia adalah aksara Ulu dan Jawi. Perbedaan utama antara aksara Surat Ulu dengan aksara Jawa ialah bahwa aksara Surat Ulu tidak memiliki pasangan sehingga jauh lebih sederhana daripada aksara Jawa, dan sangat mudah untuk dipelajari. Aksara Surat Ulu diperkirakan berkembang dari aksara Pallawa dan aksara Kawi yang digunakan oleh kerajaan Sriwijaya di Sumatera Selatan. Salah satu 
jenis aksara ulu adalah "Ka Ga Nga" Rejang dari provinsi Bengkulu. Istilah $\mathrm{Ka}$ Ga Nga diperkenalkan oleh M.A. Jaspan pada tahun 1964, dan banyak orang beranggapan aksara Rejang adalah maha karya hasil ciptaan leluhur suku Rejang sendiri yang harus kita lestarikan.

Karena semakin pesatnya pengaruh globalisasi secara tanpa kita sadari kearifan lokal asli Indonesia mulai memudar. Salah satunya adalah aksara yang merupakan tulisan yang telah berkembang sejak zaman leluhur dahulu kala. Ini adalah aset kekayaan negara yang harus dipertahankan. Maka dari itu dalam kurikulum Indonesia pemerinta memberikan wadah dalam pembelajaran muatan lokal yang mengangkat keunikan daerah masing masing.

Maka dari itu pemerintah Kabupaten Bengkulu Utara menjadi salah satu daerah yang berkomitmen untuk mewajibkan siswa dari SD samapai SMA untuk mempelajari aksara "Ka Ga Nga" Rejang. Namun pada pelaksanaannya belum maksimal, kegiatan pembelajaran masih menggunakan metode konvensional yaitu menggunakan buku teks. Sehingga membuat siswa bosan dan jenuh dalam pembelajaran. Sebagai upaya meningkatkan kualitas pembelajaran maka diperlukan media yang aplikatif. Siswa akan lebih antusias jika media yang diajarkan menyenangkan dan mudah di pahami. Sehingga peneliti memilih media aplikatif dalam pembelajaran aksara " $\mathrm{Ka}$ Ga Nga" yaitu menggunakan aplikasi dan komputer.

\section{Aksara Ka Ga Nga}

Istilah Sunda, menurut Ekadjati (1993, hlm. Aksara "Ka ga nga" merupakan sebuah nama kumpulan beberapa aksara yang berkerabat di Sumatra sebelah selatan. Aksara-aksara yang termasuk kelompok ini adalah antara lain aksara Rejang, Lampung, Rencong, dan lain-lain. Nama kaganga ini merujuk pada tiga aksara pertama yang mengingatkan kita kepada urutan aksara di
India. Istilah kaganga diciptakan oleh Mervyn A. Jaspan (1926-1975), antropolog di University of Hull (Inggris) dalam buku Folk literature of South Sumatra. Redjang Ka-Ga-Nga texts. Canberra, The Australian National University 1964. Istilah asli yang digunakan oleh masyarakat di Sumatra sebelah selatan adalah Surat Ulu.

Aksara Batak atau Surat Batak juga berkerabat dengan kelompok Surat Ulu akan tetapi urutannya berbeda. Diperkirakan zaman dahulu di seluruh pulau Sumatra dari Aceh di ujung utara sampai Lampung di ujung selatan, menggunakan aksara yang berkerabat dengan kelompok aksara Kaganga (Surat Ulu) ini. Tetapi di Aceh dan di daerah Sumatera Tengah (Minangkabau dan Riau), yang dipergunakan sejak lama adalah huruf Jawi.

Perbedaan utama antara aksara Surat Ulu dengan aksara Jawa ialah bahwa aksara Surat Ulu tidak memiliki pasangan sehingga jauh lebih sederhana daripada aksara Jawa, dan sangat mudah untuk dipelajari. Aksara Surat Ulu diperkirakan berkembang dari aksara Pallawa dan aksara Kawi yang digunakan oleh kerajaan Sriwijaya di Sumatera Selatan. Salah satu jenis aksara ulu adalah "Ka Ga Nga" Rejang dari provinsi Bengkulu.

Dalam kajian sosial budaya Rejang menjelaskan bahasa Rejang memiliki abjad tersendiri yang dikenali sebagai abjad Kaganga. Abjad Kaganga identik dengan huruf yang ada pada abjad Batak dan abjad lampung. Kemungkinan besar karena adanya asimilasi tradisi melalui informasi di masa yang tidak kita mengerti. Bahasa Rejang terbagi dari tiga kelompok dialek, yakni dialek Rejang Curup, Rejang Kepahiang, dan Rejang Lebong. Dialek yang di Kabupaten Bengkulu Utara termasuk dialek Curup, karena tidak berbeda dengan dialek Curup.

Dari tiga pengelompokan dialek Rejang tersebut, saat ini Rejang terbagi menjadi Rejang Kepahiang, Rejang Curup, dan Rejang Lebong. Namun, meskipun 
dialek dari ketiga bahasa Rejang tersebut relatif berbeda, tapi setiap penutur asli bahasa Rejang dapat memahami perbedaan kosakata pada saat komunikasi berlangsung. Karena perbedaan tersebut seperti perbedaan dialek pada bahasa Inggris Amerika, bahasa Inggris Britania, dan bahasa Inggris Australia. Secara filosofis, perbedaan dialek bahasa Rejang terjadi karena faktor jarak, faktor sosial, dan faktor psikologis dari suku Rejang itu sendiri. Hal ini juga membuktikan bahwa tingkat persatuan dan kesatuan suku Rejang masih sangat rendah jika dibandingkan dengan suku bangsa terdekat lainnya anatara suku Lembak, suku Srawai dan suku Pasemah. Itu disebabkan karena suku Rejang bukan suku bangsa perantau sehingga tingkat kepemilikan tanah mereka tergolong tinggi, mereka masih mudah dipengaruhi devide et empera yang dilancarkan penjajah sejak zaman pemerintahan Hindia-Belanda. Pada zaman sekarang, politik pecah belah tersebut dilancarkan oleh golongan tertentu dengan tujuan yang relatif sama dengan penjajahan Hindia-Belanda.

\section{Konsonan}

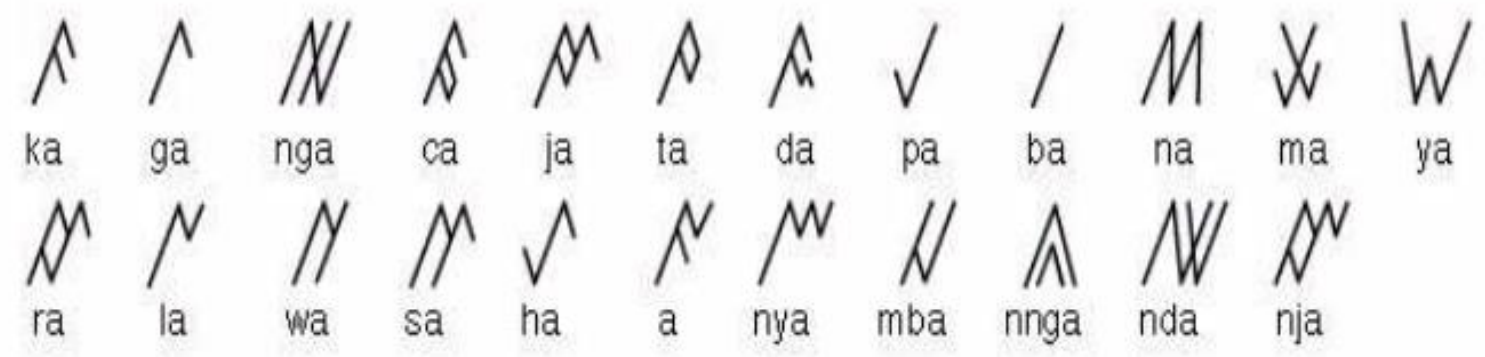

Vokal dengan aksara 'Ka'

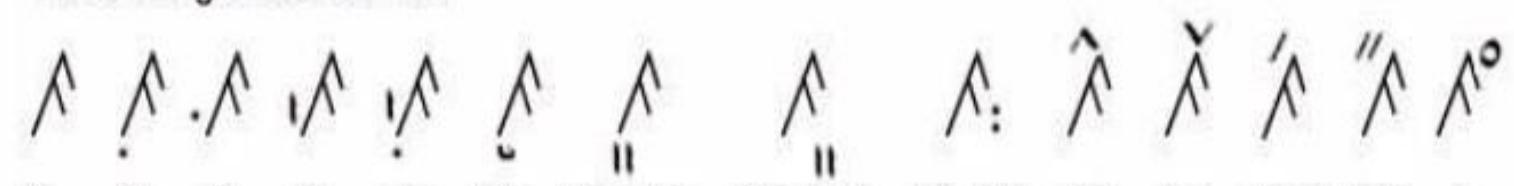

ka ku ki ké ko kau keu, ke këa, kah ka', kak kai kar kang kan -k

Aksara Kaganga

\section{Media Aplikatif}

Belajar adalah perubahan pengalaman si peserta didik yang meliputi ranah kognitif, afektif dan psikomotorik. Maka dari itu seorang guru harus terampil dalam memilih media pembelajaran agar pembelajaran berkualitas. Media (medium) adalah tehnologi untuk menyajikan, merekam, membagi, dan mendistribusikan symbol dengan melalui rangsangan indra tertentu, disertai penstrukturan informasi. Gagne dalam Sadiman et al (2008) menyatakan bahwa media pembelajaran adalah berbagai jenis komponen dalam lingkungan siswa yang dapat merangsangnya dalam belajar.

Jadi segala sesuatu yang dapat menyalurkan pesan dari pengirim ke penerima sehingga dapat merangsang pikiran, perasaan, perhatian, dan minat siswa sehingga terjadi suatu proses pembelajaran dapat dikategorikan sebagai media pembelajaran. Secara bahasa dari KBBI aplikatif /ap.li.ka.tif/ a berarti mengenai (berkenaan dengan) penerapan. Jadi media pembelajaran aplikatif adalah media pembelajaran yang dapat di aplikasikan atau diterapkan oleh siswa. 
Salah satu media yang aplikatip adalah menggunakan komputer dan aplikasi. Bentuk interaksi yang dapat diaplikasikan yaitu, praktek dan latihan (drill \&
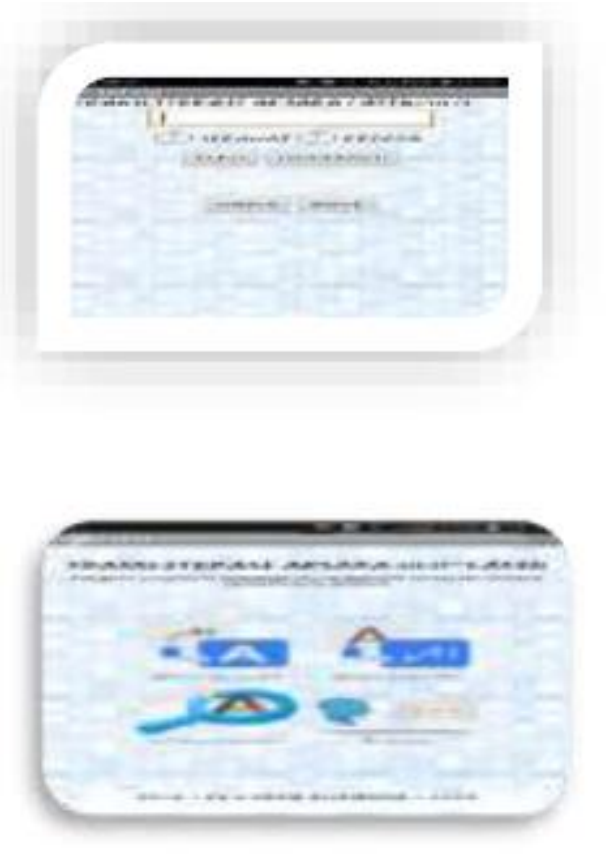

\section{Kearifan Lokal}

Kearifan Lokal terdiri dari dua kata yaitu kearifan ( wisdom ) yang artinya kebijaksanaan dan lokal ( local ) yang berarti daerah setempat. Jadi secara umum pengertian dari kearifan lokal adalah Gagasan-gagasan, nilai-nilai atau pandangan dari suatu tempat yang memiliki sifat bijaksana dan bernilai baik yang diikuti dan dipercayai oleh masyarakat di suatu tempat tersebut dan sudah diikuti secara turun temurun.

Fjarini dalam penelitiannya menyimpulkan bahwa kearifan lokal yang merupakan warisan masa lalu berasal dari leluhur yang tidak hanya terdapat dalam sastra tradisional (lisan maupun tulis) tetapi terdapat dalm berbagai bidang kehidupan nyata, seperti filosofi, pandangan hidup, kesehatan, arsitektur. Tanpa pelestarian maka kearifan lokal akan punah. Karena makin derasnya arus globalisasi.

Nadlir (2014) menjelaskan bahwa kearifan lokal diajarkan di sekolah bertujuan untuk memberikan bekal practice), tutorial, permainan (games). simulasi (simulation), penemuan (discovery), pemecahan Masalah (Problem Solving).

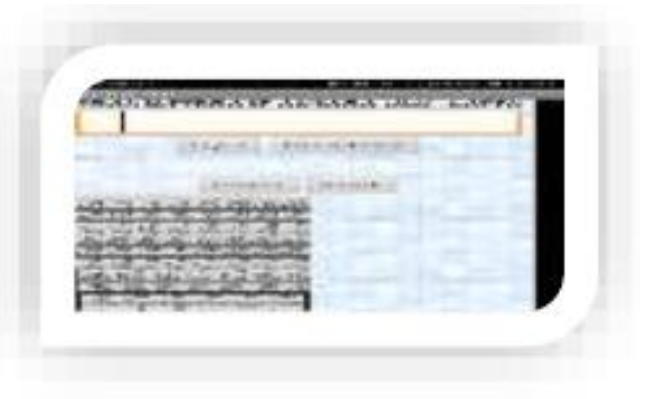

pengetahuan, keterampilan, dan perilaku kepada peserta didika agar memiliki wawasan yang mantap tentang nilai-nilai atau aturan yang berlaku di daerahnya dan mendukung pembangunan daerah.

Hal ini berkaitan dengan Peraturan Menteri Pendidikan dan Kebudayaan Republik Indonesia Nomor 79 Tahun 2014 tentang muatan lokal kurikulum 2013 pada pasal 1 ayat 1 menjelaskan bahwa muatan lokal adalah bahan kajian atau mata pelajaran pada satuan pendidikan yang berisi muatan dan proses pembelajaran tentang potensi dan keunikan lokal. Selain itu pada pasal 2 ayat 2 diperjelas bahwa muatan lokal yang diajarkan dengan tujuan membekali peserta didik dengan sikap, pengetahuan, dan keterampilan yang diperlukan untuk 1) Mengenal dan mencintai lingkungan alam, sosial, budaya, dan spiritual di daerahnya; dan 2) Melestarikan dan mengembangkan keunggulan dan kearifan daerah yang berguna bagi diri dan lingkungannya dalam rangka menunjang pembangunan nasional. 


\section{Suku Rejang}

Suku rejang termasuk salah satu suku bangsa tertua di Sumatera dan mempunyai garis keturunan yang jelas,adat dan istiadat dan tata cara yang tinggi diantara suku bangsa yang ada dimuka bumi nusantara ini. Keaslian dan dan keistimewaan suku rejang dapat ditelistik berdasarkan

\section{METODE PENELITIAN}

Metode penelitian yang digunakan dalam kegiatan ini adalah action research. Pemilihan metode ini dilakukan untuk mencari formulasi terbaik untuk pengembangan karakter dan melibatkan seluruh siswa. Menurut Taba dan Noel (1990: 67), action research memiliki tahapan yaitu: (1) identifikasi masalah, (2) analisis masalah beserta faktor penyebabnya, (3) formulasi pemecahan, (4) pencarian data pendukung, (5) formulasi aksi, dan (6) evaluasi.

\section{Populasi dan Sampel Penelitian}

Setiap penelitian, memiliki batasan yang berkaitan dengan populasi penelitian yang mempunyai arti bervariasi. Menurut Ary dkk., Populasi atau population is all members of well defined class of people, events or objects (Ary and Razavieh, 1985:138). Sedangkan Djudju Sudjana berpendapat bahwa populasi adalah merupakan totalitas semua nilai yang mungkin, hasil menghitung, mengukur, baik secara kwantitatif maupun kwalitatif dari karakteristik tertentu mengenai sejumlah objek yang lengkap dan jelas (Sudjana, 1996: 6).

Dalam penelitian ini, populasi target penelitian adalah seluruh siswa SDN Padang Bendar Bengkulu Utara kelas V (lima). keluhuran unsur-unsur kebudaayaan yang terintegrasi.dalam budaya rejang itu sendiri. Sejarah bahasa, aksara,sistem pengetahuan dan organisasi sosial,system peralatan hidup dan teknologi,sistem pencaharian hidup,sistem religi dan kesenian.

\section{Teknik Pengumpulan Data}

Penelitian ini dimaksudkan untuk memahami perilaku manusia. Untuk maksud tersebut, peneliti menggunakan pendekatan kuantitatif. Disebut kuantitatif karena sifat data yang dikumpulkannya bercorak kuantitatif, yang mengunakan angka-angka sebagai alat pengukur.

Teknik yang digunakan dalam pengumpulan data yang relevan untuk memperkuat analisis penelitian, ditempuh langkah-langkah sebagai berikut:

\section{Obervasi}

Metode pengumpulan data dengan menggunakan jalan mengamati secara langsung, yakni meneliti selama kejadian di SDN Padang Bendar Bengkulu Utara. Tujuan melakukan observasi adalah untuk melihat dan mencatat fenomena yang muncul yang memungkinkan terjadinya perbedaan di antara siswa.

\section{Kuesioner}

Kuesioner adalah serangkaian pertanyaan tertulis yang diajukan peneliti kepada para responden penelitian untuk mendapatkan jawaban secara tertulis juga. Sehubungan dengan hal itu, Kartini Kartono (1986: 217) mengemukakan: kuesioner (questioner) ialah penyelidikan mengenai suatu masalah yang banyak menyangkut kepentingan umum (orang banyak) dilakukan dengan jalan 
mengedarkan suatu formulir daftar pertanyaan, diajukan secara tertulis kepada sejumlah obyek untuk mendapatkan jawaban atau tanggapan (respon) tertulis seperlunya.

Sedangkan Sutrisno Hadi (1987 : 157), menjelaskan bahwa : "Metode kuesioner dalam bentuknya yang langsung keduanya mendasarkan diri pada laporan tentang diri sendiri atau self report, atau setidak-tidaknya pada pengetahuan yang dimiliki, atau keyakinan pribadi". Artinya bahwa kuesioner dalam penelitian ini digunakan untuk memperoleh data dan informasi yang rinci dan obyektif.

Kuesioner tersebut berupa kuesioner, tes, dan chek-list yang dilakukan baik berupa tes maupun non tes untuk menilai variabel penelitian, dan yang dijadikan sebagai responden adalah siswa itu sendiri.
3. Studi kepustakaan

Studi kepustakaan ini, penulis melakukannya dengan cara membaca, mempelajari dan meneliti berbagai sumber buku-buku yang ada hubungannya dengan pendidikan karakter.

\section{Teknik Analisis Data}

Teknik analisis data yang digunakan adalah analisis deskriptif kualitatif dan kuantitatif. Analisis deskriptif kualitatif ditampilkan dalam bentuk tabel dan matrik yang menggambarkan tentang pencapaian program. Analisis kuantitatif digunakan untuk menganalisis perubahan karakteristik responden sebelum dan sesudah pelaksanaan kegiatan. Dalam analisis kuantitatif, pengolahan data mengggunakan program Statistical Package for Social Science (SPSS).

\section{BIAYA DAN JADWAL KEGIATAN}

\begin{tabular}{|l|l|l|}
\hline No & \multicolumn{1}{|c|}{ Jenis Pengeluaran } & \multicolumn{1}{|c|}{ Biaya (Rp) } \\
\hline 1. & Peralatan penunjang & Rp. 3.000 .000 \\
\hline 2. & Bahan habis pakai & Rp. 2.000 .000 \\
\hline 3 & Perjalanan & Rp. 5.00 .000 \\
\hline 4 & Lain-lain: Administrasi,publikasi,seminar,laporan & Rp. 2.500 .000 \\
\hline & Jumlah & Rp. 11.000 .000 \\
\hline
\end{tabular}




\begin{tabular}{|l|l|l|l|l|l|l|}
\hline \multirow{2}{*}{ No } & \multirow{2}{*}{ Jenis Kegiatan } & \multicolumn{5}{|c|}{ Bulan } \\
\cline { 5 - 7 } & $\mathbf{1}$ & $\mathbf{2}$ & $\mathbf{3}$ & $\mathbf{4}$ & $\mathbf{5}$ \\
\hline 1 & Observasi & & & & & \\
\hline 2 & Studi Pendahuluan & & & & & \\
\hline 3 & $\begin{array}{l}\text { Pembuatan } \\
\text { Instrumen }\end{array}$ & & & & & \\
\hline 4 & $\begin{array}{l}\text { Perancangan } \\
\text { Perangkat penelitian }\end{array}$ & & & & & \\
\hline 5 & $\begin{array}{l}\text { Pelaksanaan } \\
\text { penelitian }\end{array}$ & & & & & \\
\hline 6 & Pengolahan data & & & & & \\
\hline 7 & Laporan & & & & & \\
\hline 8 & Seminar & & & & & \\
\hline
\end{tabular}

\section{KESIMPULAN}

\section{Tujuan Khusus}

Berdasarkan rumusan masalah di atas, maka penelitian ini bertujuan khusus untuk:

1 Untuk menguji efektivitas penggunaan media aplikatif pada pembelajaran aksara Rejang “Ka Ga Nga”Untuk mengetahui huruf aksara ka ga nga

2 Untuk upaya pelestarian kearifan lokal aksara dari Suku Rejang di Kabupaten Bengkulu

\section{Urgensi (Keutamaan Penelitian)}

Keutamaan atau urgensi dari penelitian ini adalah diharapkan ditemukannya pengembangan untuk pelastarian aksara "Ka Ga Nga" agar mencegah terjadinya kepunahan. Meningkatkan antusias belajar siswa melalui media aplikatif dalam pembelajaran aksara "Ka Ga Nga". Temuan yang ditargetkan pada penelitian ini yaitu modia pembelajaran aplikatif untuk meningkatkan kecintaan siswa terhadap aksara Rejang.

\section{Luaran penelitian}

Luaran dari penelitian ini yaitu mengembangkan keilmuan mengenai media pembelajaran aplikatif aksara "Ka Ga Nga" Rejang dan menjadi referensi bagi masyarakat yang belum melaksanaknnya khususnya di wilayah Bengkulu Utara. Publikasi artikel ilmiah dari hasil penelitian berbentuk Jurnal pendidikan dasar p-ISSN 2086-7433 (cetak) e-ISNN 2549-5801 (online). Mengikuti Seminar Nasional yaitu menjadi pemakalah atau presenter.

\section{Manfaat Penelitian}

Manfaat dari penelitian ini adalah sebagi berikut:

1 Bagi peneliti;

Hasil dari penelitian ini beguna untuk menambah pengetahuan akan pentingnya pelestaraian aksara " $\mathrm{Ka} \mathrm{Ga}$ 
Nga" yang diaplikasikan dengan efektif dan menambah wawasan tentang aksara "Ka Ga Nga" serta rasa cinta terhadap peningalan budaya;

2 Bagi guru;

Hasil penelitian ini dapat memberikan wawasan dan keterampilan untuk mengaplikasikan aksara "Ka Ga Nga" suku rejang di Sekolah Dasar serta

\section{REFERENSI}

Arikunto Suharsimi dkk.(2009). Penelitian Tindakan Kelas Jakarta : Bumi Aksara

Ilham Alfian Nor (2009).Media Pembelajaran.

http://simpangmahar.blogspot.co.id/2 $\underline{010 / 02 / \text { media-pembelajaran.html }}$

Kamus Bahasa Indonesia https://kbbi.web.id/aplikatif

Mc Ginn, Richard.Asal Bahasa Rejang. www.ohio.edu/people/mcginn/Lingu a_charis_SIL.pdf oleh BRTRS Malagasy.

Ekorusnoyo dan Imron Rosyadi. Roh Kehidupan Suku Rejang. Yogyakarta: Buku Litera,2015. meningkatkan rasa nasionalisme terhadap jiwa guru;

3 Bagi siswa;

Hasil dari penelitian ini berguna untuk mengantarkan para siswa di tingkat sekolah dasar untuk mengembangkan karakter untuk mencintai budaya dengan mengaplikasikan aksara "Ka Ga Nga" serta memupuk rasa nasionalisme siswa di sekolah dasar.

Harsono, Pengelolaan Pembelajaran Muatan Lokal Bahasa Daerah (Studi Kasus di dua SMP Negeri Kota Surakarta, Jurnal Eksplanasi Vol 4 (8),Edisi Oktober 2009.

Hasan, Zulman. Anak Kutai Rejang. Sejarah Adat Budaya Berbahasa dan Aksara,Lebong:Dinas Pariwisata dan Kebudayaan Kabupaten Lebong,2015.

Muktadir Dan Agustrianto.Jurnal Pendidikan Karakter. http://journal.uny.ac.id/index.php/cp/ index.Home No 3.2014

Sukmadinata, N.S. (2010). Metode Penelitian Pendidikan.Bandung: PT Remaja Rosda Karya 